\title{
Family Policy: an integrated approach?
}

\author{
David Marjoribanks* \\ Relate
}

Keith Davies*

Kingston University

\begin{abstract}
Following the result of the EU Referendum and the emergence of a new Prime Minister the direction of family policy in England remains to be clarified. The future of flagship initiatives of the previous administration such as the Troubled Families Programme and the Life Chances Strategy remain uncertain. Taking advantage of the hiatus to take stock, this article raises concerns regarding the effects of previous ad hoc family policy development with particular reference to parenting support and relationship support. Borrowing an emphasis on coherent, coordinated service provision and 'whole-family' approaches from the Troubled Families Programme alongside the 'life course' narrative of the Life Chances Strategy, it is argued that these concepts offer the framework for a more integrated family policy including both universal and targeted elements.
\end{abstract}

Key words: life chances, life course, whole family, relationship support, parenting support.

\section{Introduction}

Policy addressing poverty, life chances and the family awaits a new direction in England following the result of the EU Referendum on the 23rd of June 2016 and the resignation of David Cameron the following day. Although the rhetoric of the Prime Minister Theresa May has reflected support for the 'working class family' and opposition to 'burning injustices' such as racism and the limited life chances which poverty most often brings (May, 13th July 2016), detailed policy has yet to emerge. This is, therefore, an opportune moment to consider recent trends in policy and to look ahead.

This article considers the 'Life Chances Strategy' (Cameron, 2016) of the Cameron administration and argues for a more integrated, coordinated form of policy development. It stresses the recognition and inclusion of all family types, defining the term family widely and inclusively whilst, at the same time, envisaging a spectrum of services, both targeted and universal, which any family might use and move on from as it responds to changes, crises and opportunities over time. It draws on two key concepts, both of which might contribute towards the formation of a more unified life chances policy. The first of these is the concept of the 'life course,' present in the nowsuspended Life Chances Strategy (LCS) and explored in the academic arena by writers 
such as Green (2016). The second is the 'whole family' concept (Morris et al., 2008), central to the Troubled Families Programme (Davies, 2015) and its predecessors the Family Intervention Projects. Central to this concept is the understanding of a family, however configured, as an inter-related entity around which services should cohere (by contrast with a model whereby a plethora of agencies deal separately with individual family members without reference to either each other or to others in the family). Using these concepts and focusing on the early years and, in particular, parenting support and relationship support, the article seeks to illustrate ways in which an evidencebased and integrated life chances strategy might be envisaged.

\section{The (late?) 'Life Chances Strategy’}

David Cameron had planned to launch of the Life Chances Strategy on 24th June 2016, immediately after the EU Referendum. Instead he resigned and the strategy entered a state of limbo. Despite this, the Life Chances Strategy, announced in a key speech earlier in the year (Cameron, 2016), represents a helpful point of departure for a consideration of integrated policy.

Rhetorically ambitious, the Life Chances Strategy promised an 'all-out attack on poverty' and envisaged a role for government in improving equality of access to life chances albeit in the context of continued austerity and overall reductions in public expenditure. Pertinently for this discussion, it began by arguing that reductions in poverty and the realisation of more equality of opportunity require 'a more social approach' over and above the traditional, liberal economic reliance upon economic success summed up in the mantra that a 'rising tide raises all boats.' This 'more social' policy was envisaged as:

One where we develop a richer picture of how social problems combine, of how they reinforce each other, how they can manifest themselves throughout someone's life and how the opportunity gap gets generated as a result. (Cameron, 2016)

In recognising the interrelatedness of social disadvantages, how they might magnify each other and operate in different ways at different points in a person's life, the Life Chances Strategy, it is argued, began to envisage an approach which reflects complex lived experience more closely.

The Prime Minister's speech on life chances was presented in four parts, each one reflecting in chronological sequence a stage of the human life course. The first part, on which this article concentrates, focused on the early years and placed an emphasis on the role of good parenting in child development. In doing so it drew on the not uncontroversial findings of neuroscientific research regarding parenting and infant brain development (Shonkoff and Fisher, 2013; Wastell and White, 2012). A number of family and early years initiatives were included and, amongst these, was a doubling of the funding for relationship support (delivered through organisations such as Relate and One-Plus-One) to $£ 70$ million. In addition, 'parenting skills and child development' would be woven closely into the targeting and delivery of the expanded second phase of the Troubled Families Programme. Importantly, beyond targeted help for parents in most need, a case was made for universal parenting support promising that the Life Chances Strategy would contain plans for increased provision in parenting support and an investigation into the feasibility of a voucher scheme to encourage the widest participation. 
In the end though, getting parenting and the early years right isn't just about the hardest-to-reach families, frankly it's about everyone. We all have to work at it. (Cameron, 2016)

The second domain considers schooling, the curriculum, teaching methods and, in particular, the fostering of 'character and resilience.' These last two somewhat traditional qualities are understood in the context of recovery from failure and the persistence needed to overcome obstacles and set-backs. An expansion of the National Citizenship Service was envisaged as playing an important role at this point. Proceeding chronologically, the speech then considered opportunities for young people, particularly in employment. Recognising that disadvantage can entail limited networks and opportunities, the LCS included 'a new national campaign...to build a new generation of high-quality mentors' whilst, at the same time, championing greater availability of work placements. Finally, in the fourth, adult phase, it focused on mental health and included more money for 'evidence-based specialist mental health care during or after pregnancy', psychiatric liaison services in A\&E and community-based mental health services.

At the point of Cameron's departure, it was, therefore, possible to detect some seeds of policy integration in the 'more social' rhetoric, the life course framework and the whole family notion associated with the Troubled Families Programme. However, the potential for cohesion and for reflecting complex, ever-evolving experience is barely exploited. The parts of the strategy are presented with minimal reference to each other and there is little sense that families of whatever structure might comprise people at different life stages facing interrelated challenges and opportunities. The apparently piecemeal nature of policy development and the lack of coordination between initiatives announced gave rise to concern that an opportunity was being missed to create a genuinely integrated approach.

Taking examples from the family and early years section of the strategy, despite the established association between good parental relations and successful child development (Harold et al., 2016), it remained unclear to what extent new support for relationships between parents would be linked with the expanded parenting classes and vice versa. There was also little indication regarding how the new initiatives in relationship support and parenting might link with existing services such as Children's Centres or the provision of perinatal care and this is coupled with a lack of guidance regarding how initiatives in other elements of the Life Chances Strategy, such as mental health services for women and young people, might be connected with other proposals associated with different parts of the life cycle. More broadly, it was also unclear how targeted and universal elements of the strategy would work together. It should also be noted that funds were not committed to the universal voucher scheme for parenting support, this remaining a notably aspirational idea.

Taking these concerns as a starting point, this article explores the danger of 'fragmentation' (Marjoribanks, 2016) for future 'life chances' policy-making and does so in particular by considering proposed developments in relationship support and parenting support. It seeks to trace ways in which the life course and whole family thinking might build on the existing evidence base to create a more coherent, integrated field of policy-making. 


\section{Reasons for the 'relational turn': Why parenting and family relationships are on the policy agenda}

The current policy interest in families and relationships has built arguably both in response to growing awareness of the importance of family for children's outcomes, and also, in a context of continuing austerity, the pressure to reduce the costs to the state associated with the negative impacts of poor quality relationships and relationship breakdown.

Research has increasingly demonstrated that poor quality family relationships and fractious family separations can have detrimental impacts on children's wellbeing, which in some cases can last in the long term. For example, it is now well-established that, although most children whose parents separate or divorce do not experience adverse outcomes, poor outcomes such as behavioural difficulties are around twice as likely for these children as they are for children whose parents remain together (Pryor and Rodgers, 2001). Policy-makers have therefore increasingly come to see the importance of supporting family relationships to reduce rates of family breakdown and/or mitigate the harm to children. The Coalition Government made family breakdown one of the five 'pathways to poverty' and increased the investment from the state into relationship support - which the subsequent Conservative Government had promised to double (Cameron, 2016).

It is important, however, to note the evidence also indicates there are important mediating factors which explain why some children are negatively affected while most are not. For example, the presence of poverty post-separation accounts for many of the negative outcomes experienced (Burghes, 1994), and the quality of the relationships surrounding the child are crucial (Smith and Trinder, 2012). Research shows that the negative impacts of parental relationship dissolution on children are predominantly rooted in the compounding conflict (Amato, 2006; Cummings and Davies, 2002). A now substantial body of evidence highlights the central role of inter-parental relationship quality, and specifically the presence of conflict, in determining children's outcomes. A recent evidence review for the Department for Work and Pensions (Harold et al., 2016) concluded that the quality of the inter-parental relationship is a 'primary influence' on effective parenting and children's long-term mental health and future life chances. Parental conflict can affect children's and adolescents' wellbeing, adjustment, and both their emotional and mental development (Cummings and Davies, 1994) resulting in increased levels of anxiety, depression, aggression, hostility, antisocial behaviour and even criminality (Harold and Leve, 2012). It is now recognised that the way in which a family functions and the quality of the relationships, both in intact and separated families, are crucial determinants of children's mental health and wellbeing, educational achievement, and future life chances.

The other driver of family relationships onto the policy agenda is, of course, financial. The economic cost of relationship breakdown has been estimated at $£ 48$ billion in 2016 (Relationships Foundation, 2016), and much of government rhetoric around the Troubled Families Programme, for example, has centred on the 'cost' these families are said to entail for the state. The Government claimed 120,000 families cost the state approximately $£ 9$ billion a year ( $£ 75,000$ per family), $£ 8$ billion of which was deemed 'reactive' spending (HM Government, 2011). Cost has also been a major driver of reform to the family justice system and of efforts to shift more separated families away from statutory systems (the courts, the child maintenance system).

These two major drivers of policy, finances and children's outcomes, have therefore increasingly focused policy-makers' attention on relationships and family functioning. The Coalition Government's Social Justice Strategy highlighted the importance of family 
relationships for social justice, recognising that strong and stable families provide children with the best start in life (HM Government, 2012), and the Conservative Government pursued this agenda further in its 'life chances' approach to root causes of poverty, including family breakdown (DWP, 2015a).

\section{Universal and targeted dynamics within the 'relational turn' in policy}

However, we may detect different dynamics within recent family policy, which have coexisted within policies of recent governments. In particular, we can see two different approaches within the increasing focus on families and relationships in policy: a targeted approach where family and relationship support is aimed at specific groups to achieve particular ends in response to particular issues; and a universal approach in which family and relationship support is offered to and encouraged for all.

Within the former approach, family and relationship support is aimed at particular groups for particular purposes, for example, at harder-to-reach groups (such as young parents) or those with greater needs. Approaches which target hard-to-reach groups (e.g. 'Troubled' Families) rather than people periodically in greater need due to life transitions can often be constructed around a 'deficit model' of family and relationships, whereby family or relationship support is seen as a solution to a particular problem (e.g. poverty; worklessness and benefit dependency, antisocial behaviour, criminality), which, it is recognised, has roots in the family circumstances: for example, dysfunctional parenting, parental conflict, domestic violence, etc. In this sense, family and relationship support is a state intervention in family life as a 'corrector' - a sort of proxy-parent to help turn things around. Such approaches can sometimes appear 'othering' and stigmatising. However, not all targeted approaches are deficit-based. Support for people going through particularly challenging life stages (e.g. the transition to parenthood) is 'targeted' towards this particular demographic, but within a universalistic framework. Thus there is no clear-cut line to be drawn between the two dynamics.

The universal dynamic opens up the field of support to everyone, for all levels of need, highlighting the universality of relationship and family pressures within a common life cycle. Here it is recognised that we all need to work at our relationships, all relationships can come under strain at particular points of change or stress, and support therefore needs to be available to, and marketed at, everyone, regardless of situation. Family and relationship support is here seen not as a solution to a problem but rather as a means of strengthening relationships and families against common pressures, instilling resilience, and enhancing family functioning - with benefits for children's and adults' health and wellbeing.

Both dynamics have been at work within the turn to family and relationships in policy over recent years. For example, the 1998 Green Paper on the family, Supporting Families, the first ever such Green Paper on the family (HM Government, 1998), contained many policies aimed at changing family behaviour, improving parenting, tackling domestic violence, reducing teenage pregnancy, etc. Yet alongside these targeted and deficit-based policies were also more universalistic policies around balancing work and family, strengthening marriage, support for all parents, increasing availability of counselling before divorce and relationship support around the time of the birth of a child. Unfortunately, however, the distinct focus on the family and relationships in Supporting Families was largely forgotten about for the remainder of the Labour Government, and it was not developed into a coherent 'family policy' as a specific area of activity (Millar, 2001). 
With the riots of 2011, a deficit-model, targeted approach to family support reemerged squarely on the agenda (having appeared a few years earlier, in the Social Exclusion Taskforce's 'Think Family' agenda) in the form of the Troubled Families Programme, beginning initially with 120,000 families, and extended in 2015 to a further 400,000 families (DCLG, 2013). Despite the large expansion, it remains a firmly targeted approach and both the Think Family agenda and its Troubled Families progeny have limited the whole-family and relational approach to families at risk and with problems.

However, the universal approach has also gathered pace. Research undertaken for Department of Children \& Family Services (DCSF) in 2010 highlighted how all families face stressors in their relationships at one point or other as members negotiate the life course alongside each other and that everyone can benefit from better information, education and access to support services around particular life stages (Walker et al., 2010). For example, evidence shows that becoming a kinship carer (Farmer and Moyers, 2008) and caring for a disabled child (Glenn, 2007) place particular strain on relationships, while more universally, becoming a parent is one of the most stressful life events (Walker et al., 2010) and is therefore one of the life events most likely to reduce relationship quality (Cowan et al., 1991). First-time parents are at risk of experiencing personal and marital distress (Twenge et al., 2003; Mitnick et al., 2009; Mansfield and Collard, 1998; OnePlusOne, 2006), and it is estimated that $40-70 \%$ of couples experience a decline in relationship quality in their first year of parenthood (Shapiro and Gottman, 2005). Government has therefore focused on support around this life transition within its relationship support funding, for example by producing guidance for health visitors to support them to spot signs of relationship distress and to respond by supporting new parents, as well as piloting relationship support within perinatal provision (DWP, 2015b).

Continuing the universal dynamic, in 2010 David Cameron announced his intention to lead the 'most family friendly Government we've ever had in this country', highlighting that 'that is about everything we do to support families and it's about supporting every sort of family' (Cameron, 2010). Over 2011-15 the Government invested $£ 30$ million in relationship support, in addition to other universalistic family and relationship support policies including the CANparent parenting voucher scheme, and shared parental leave, whilst also introducing the 'Family Test' in October 2014, which requires all new policies across Whitehall to consider the impact they might have on family relationships (HM Government, 2014).

Seen within this context, the Prime Minister's announcements in his 2016 'life chances' speech of doubling funding for relationship support, making parenting support 'aspirational' and universal, and a new focus on parenting and child development within the Troubled Families Programme clearly continue both of these universal and targeted dynamics within recent family policy.

\section{Challenges for integrated family policy}

There are a number of generic challenges in family policy which have arguably inhibited the development of an integrated, coherent approach. Firstly, the diversity of family forms: relationships and family life are continuing to change both in structure and functioning. Declining marriage rates, for example, are giving rise to increasing numbers of cohabiting families (the fastest growing family type in the UK (ONS, 2015)) whilst higher rates of children not living with both parents are continuing to change the shape of families. Furthermore, there are now seven million unpaid carers in the UK, expected to reach over 10 million over the next 30 years (Carers Trust, 2014). As 
family members age, the role of carer can arise at the same time as other family members need increased attention, for example, in adolescence. Working patterns are also changing and today one-in-three working mothers is now the main breadwinner for the family (IPPR, 2013). These ongoing shifts in patterns of family life present a challenge to a 'family policy' as a distinct area of government activity: definitions of 'the family' employed must be suitably inclusive, open to the views of families themselves (Morris, 2013) and sensitive to changes over time. The 'Family Test', for instance, utilises a helpfully inclusive concept of 'family', including couple relationships, loneparent and step-family relationships and extended families (DWP, 2014).

Secondly, there remain polarised views about the limits of acceptable state intervention in private family life, and family policy has long been a controversial area. The Government's response to the 1998 Supporting Families consultation, for example, noted that a similar number of responses felt that the proposals did not go far enough to strengthen marriage as felt they focused too heavily on marriage at the expense of other relationships (Home Office, 1999). The Government has also come under fire from some for supporting marriage, including during the Coalition from the then Deputy Prime Minister (Clegg, 2011). As has been noted by others, family policy is more directly normative than many other policy areas and depends on shared values (Millar, 2001), yet it is clear that there continue to be different, and often quite polarised, views about the role of the state vis-à-vis the family and its structures and processes.

Thirdly, a continuing challenge has been the under-representation of men in relationship and family support services. Whilst research indicates that stigma around help-seeking can be a significant barrier to support in general, this particularly affects men. Men are less likely than female counterparts to access counselling and health services generally, and research shows the most commonly chosen response option among men asked about what they would do when facing relationship difficulties is not to consult anyone (Gabb et al., 2013). This is an issue for family services more generally: in 2008, DCSF-commissioned research found family services tended not to be father-inclusive (Page et al., 2008). Despite adopting a 'whole family' approach, there is evidence that men are less likely to engage with the Troubled Families Programme (Jones et al., in Davies, 2015)

\section{Evidence for relationship and parenting support}

Despite these challenges, the growing evidence has pushed family and relationships up the policy agenda. The evidence has been growing both for the centrality of family stability and parental relationships to children's outcomes, as outlined above, and for the efficacy of relationship support interventions. International evidence from a host of studies, including several randomised controlled trials indicates that relationship counselling or therapy can be effective in improving relationship quality, relationship satisfaction, conflict resolution skills, wellbeing and mental health (Shadish and Baldwin, 2005; Lebow et al., 2012; Klann et al., 2011). A review of six previous metaanalyses of studies comparing couple therapy against no-treatment control groups found those in therapy were better off at the end of counselling than 80 per cent of those assigned to the no-treatment group, with an overall mean effect size of 0.84 (Shadish and Baldwin, 2003). An evaluation of relationship counselling in the UK found Relate's couples counselling resulted in positive changes in individuals' relationship quality, wellbeing and communication (Spielhofer et al., 2014).

The evidence has similarly been growing behind parenting support. International evidence shows well-implemented parenting programmes can be effective in 
significantly improving parenting quality, thereby reducing children's problem behaviour. There are a number of well-validated programmes such as Incredible Years which has been found to improve parent-child relationships and child behaviour (Beckett et al., 2012), with a recent UK study finding improvements in child behaviour at 18 months following intervention (Bywater et al., 2009). The Department for Education-commissioned evaluation of the Parenting Early Intervention Programme (PEIP), which provided funding to local authorities to deliver evidence-based programmes, found positive effects on parents' mental wellbeing and children's behaviour, with outcomes maintained a year on (Lindsay et al., 2011).

However, these policy areas - relationships and parenting - have been relatively 'siloed', and the need for parenting interventions to address the wellbeing of parents and their relationships to each other, and the impacts of these on parenting has been less well-recognised (Roberts et al., 2009). Parenting support often focuses exclusively on parental behaviours, skills and techniques, missing the quality of inter-parental relationships, with only a handful of parenting programmes having addressed relationships (Adler-Baeder et al., 2013). However, there is good evidence that parenting support which focuses on the inter-parental relationships rather than simply parents' skill and behaviours is effective, resulting in parenting styles becoming more responsive, appropriately structured, and less harsh. Parents enjoyed better relationship quality and their children showed fewer academic, social and emotional behaviour problems over the next ten years (Cowan and Cowan, 2005). There is even evidence from several longitudinal, randomised controlled studies indicating that parenting approaches which incorporate a focus on the quality of the parental couple relationship and simultaneously aim to improve parenting skills and relationships within families rather than parenting skills alone are more effective than those which maintain an exclusive focus on individual parent-child relationships and behaviours at maintaining couple relationship quality, reducing harsh parenting, reducing academic, social and emotional behaviour problems in children, and reducing parenting stress (Cowan and Cowan, 2000; 2005; 2008). A recent evidence review for the DWP concluded that, in a context of ongoing inter-parental conflict, targeting only the parentchild relationship (i.e. parenting) does not lead to sustained positive outcomes for children, and argued that it is important for policy-makers and commissioners to consider both the couple and parenting relationship (Harold et al., 2016).

\section{How might integration be achieved?}

So what might an integrated and coherent approach to family, relationships and parenting policy look like? Clearly, we cannot here paint a detailed picture of what an integrated family policy and the mechanisms to deliver it would entail. We may, however, point to some key areas.

A coherent and integrated family policy would ensure that supporting families and relationships is recognised as a core, shared objective across current policy and practice 'silos'. The Family Test (HM Government, 2014) is therefore a welcome start, intended to bring an explicit family-focus into policy-making across all domestic policy, by examining the impact of all new domestic policy on the family as part of the impact assessment process, and it potentially paves the way for a joined-up focus on family relationships across policy silos. The stated objective of the Test is to introduce a family perspective into the policy-making process and make sure that potential impacts on family relationships and functioning are made explicit and recognised. Thus far, the response of government departments has been patchy, and the majority of departments have shown limited commitment to implementing the Test, with very few 
published assessments or demonstrations of application (Family and Childcare Trust, Relate, and Relationships Foundation, 2016). Nonetheless, the Family Test has the potential to achieve a more joined-up focus on family relationships in policy if it is embedded meaningfully and applied consistently, early on in the development of policy, in ways which are transparent and open to scrutiny. If the Test were to be given a statutory footing, and departments were required to publish a record of Family Test assessments, for example, it could provide an important mechanism for coordinating family policy across government.

Integrated family policy requires integrated delivery mechanisms, coordination "on the ground' of public services, and a shift in public service design and delivery away from a 'transactional' approach which sees services as 'goods' exchanged with service users to a 'relational' approach which nurtures relationships between people and brings them together to help each other (IPPR, 2014).

The Troubled Families Programme has been well-served neither by excessive claims of effectiveness by government nor by the payment by results mechanism and the associated criteria by which families can be judged as 'turned around' (Crossley, 2015; Davies, 2015). However, there are important lessons for policy to be drawn from the practice model recommended by the Troubled Families Programme, which not only attempts to work in concert with all family members, recognising their interconnectedness, but also to reform the way services around the family interact with them. Public services are often designed and delivered with a focus only on the presenting need of an individual at a particular time, failing to consider the service user within the context of their wider interactions and shared practices. The Troubled Families Programme's predecessor, the 'Think Family' agenda, recognised the 'need to develop the capacity of systems and services to "think family" (Social Exclusion Taskforce, 2007), observing that the 'tendency to individualise approaches to family difficulties can mean that the significant strengths demonstrated by even the most marginalised families can be overlooked.' The Troubled Families Programme has countered this tendency with a whole-family approach (Davies, 2015) and a coordinated 'whole services' response (Davies, 2015) which begins from the family and focuses on systems-change to re-orientate interventions with the family at the centre.

This approach could be deepened and broadened, embedding such relational thinking across public services across the whole continuum of needs, from universal family support services to more targeted interventions for at-risk groups. Relate have argued for a 'whole-systems' approach to supporting family relationships in which supporting relationships is recognised as a core, shared objective across public services (Marjoribanks, 2016). Such an approach would create a seamless pathway from generic to specialist support and from universal to targeted services according to the needs of different individuals, families and communities. This would also enable a shift towards a life-course approach to families and relationships in policy which would reflect the different challenges and needs experienced by family members simultaneously, increasing the awareness of those responding to one set of needs to the simultaneous existence and impact of others. Such an approach might, for example, better recognise the role many older people play as grandparents in the lives of many children; the potential impact of breakdown in older adults' relationships on wider families and the potential impact that strains on relationships between older and younger adults (e.g. burdens of caring) within families may have on wider family dynamics. A life-course perspective would also coherently bring together targeted and universal forms of support, locating support within a spectrum of needs, from promoting good quality family relationships and embedding relational capability across society, through targeted support to prevent distress at key times of transition (such as 
parenthood, illness, loss of work, becoming a carer, etc.) to support and protection for people in acute crisis.

One option for delivering this which is gaining increasing policy interest is the potential for developing Children's Centres into Family and Relationship Centres (e.g. Marjoribanks, 2016; CSJ, 2014: 4Children, 2014). The strong evidence on the links between couple relationship quality, parenting and child wellbeing (e.g. Gerard et al., 2006) presents a compelling case for co-locating or at least coordinating local family support, bringing together parenting support, relationship support and wider family services. This would provide a more integrated wrap-around family and relationship support offer. Such Family and Relationship Centres would help to increase the accessibility and also the navigability of family support, effectively coordinating at the point of delivery a range of family and relationship support services into coherent pathways for users, and would therefore prove vital delivery agents for a coordinated family policy from government. Coordinating services locally in this way could also provide valuable opportunities for fostering productive cross-professional relationships leading to better referrals and joint working.

Finally, if a unified family policy is to be achieved, this requires coordination from within government through national leadership and coordinated policy development, for example through a cross-governmental 'Supporting Families and Relationships Strategy'. A major obstacle to more coordinated family policy-making is the way in which responsibility for this area is currently dispersed across different government departments, including DWP, DfE, the Home Office, DCLG, DoH and MoJ. Fragmentation of responsibility for relationships across government leads to policymaking around relationships in distinct 'silos', lacking a coherent strategy. Against this backdrop of fragmentation, it was perhaps unsurprising that it was not clear how far the announcements on parenting, relationship support and the Troubled Families Programme contained in the Life Chances Strategy (Cameron, 2016) would be coordinated.

There are signs of promise, however. The Social Justice Cabinet Committee, established by the Social Justice Strategy but now apparently replaced by the new Social Reform Cabinet Committee (https://www.gov.uk/government/news/pmreaffirms-commitment-to-bold-programme-of-social-reform), could be a valuable vehicle for coordination. The Government recognised that the strategy required "national leadership and a change in the way that policy is created and evaluated in central government", and created the Committee to bring together ministers from across government to provide political leadership and oversee setting of priorities, actively encourage and support cross-government working" (HM Government, 2012). Ministers have stated that the Social Justice Cabinet Committee played a role "supporting crossgovernment Family policy priorities" (Altmann, 2016) and existed to "bring together all work on families and children and to ensure that we have a concerted, single approach to it" (Duncan Smith, 2015). A cross-government national strategy setting out national objectives in terms of improving family functioning and family relationship quality, supported by a similar cross-government committee (perhaps the new Social Reform Committee) would deliver a much more coherent framework for designing and delivering these different policy initiatives, starting from shared objectives, fitting the pieces of the puzzle together.

At the present time of flux in politics and policy, the direction for family policy is unclear. However, as Theresa May's government sets a course in social reform more broadly and early years and family policy more particularly, we have identified promising indications for how services might both complement each other and fit the multi-faceted and interrelated lives and needs of service users. The Family Test and the Social Reform Cabinet Committee offer potential for awareness and coordination 
across ministries whilst a life course and whole family narrative provide a valuable opportunity for coordination and integration of family policy. These opportunities should not be missed.

*Correspondence address: David Marjoribanks, Policy and Public Affairs Manager, Relate, 24-32 Stephenson Way, London, NW1 2HX. Email: David.Marjoribanks@relate.org.uk / Keith Davies, Associate Professor, Department of Social Work, Kingston University, KT2 7LB. Email: K.Davies@sgul.kingston.ac.uk

\section{References}

4Children (2014) Children \& Family Hubs: 4Children's integrated model for effective children and family support.

Adler-Baeder, F., Calligas, A., Skuban, E., Keiley, M., Ketring, S. and Smith, T. (2013) Linking Changes in Couple Functioning and Parenting Among Couple Relationship Education Participants. Family Relations, 62, 284-297.

Altmann, R. (2016) HL Deb, 25 April 2016, cW. Available from: https://www.theyworkforyou.com/wrans/?id=2016-0411.HL7514.h\&s=supporting+crossgovernment+Family+policy+priorities+speaker\%3A25445\#gHL7514.rO [Accessed: 04/11/2016]

Amato, P. (2006) Children of divorce: What we know and what we need to know. Paper presentation, International Conference on Children and Divorce, Norwich, UK, 2427 July.

Beckett, C., Beecham, J., Doolan, M., Ford, T., Kallitsoglou, A., Scott, S. and Sylva, K. (2012) Which type of parenting programme best improves child behaviour and reading:? The Helping Children Achieve trial. London: Department for Education

Burghes, L. (1994) Lone parenthood and family disruption: The outcomes for children. London: Family Policy Studies Centre.

Bywater, T., Hutchings, J., Daley, D., Whitaker, C., Yeo, S., Jones, K., Eames, C. and Edwards, R. (2009) Long-term effectiveness of a parenting intervention for children at risk of developing conduct disorder. British Journal of Psychiatry, 195, 318-324.

Cameron, D. (2010) Mending Our Broken Society. speech, 22 January

Cameron, D. (2016) Prime Minister's speech on life chances. 11 January 2016 https://www.gov.uk/government/speeches/prime-ministers-speech-on-lifechances

Carers Trust (2014) Key Facts About Carers. http://www.carers.org/key-facts-aboutcarers. Accessed December 2014.

Centre for Social Justice (2014) Fully Committed? How a Government could reverse family breakdown. London: CSJ

Clegg, N. (2011) The Open Society speech, 19 December 2011

Cowan, C.P. and Cowan, P.A. (2000) When partners become parents : the big life change for couples. Mahwah, NJ: Lawrence Erlbaum Associates

Cowan, C., Cowan, P., Heming, G. and Miller, N. (1991) Becoming a family: marriage, parenting and child development. In: Cowan, P. and Hetherington, M. (Eds.) Family Transitions. Hillsdale, NJ: LEA, 1991.

Cowan, C.P. and Cowan, P. (2005) Two central roles for couple relationships: breaking negative intergenerational patterns and enhancing children's adaptation. Sexual and Relationship Therapy. 20(3) 
Cowan, P. and Cowan, C.P. (2008) Diverging family policies to promote children's wellbeing in the UK and US: Some relevant data from family research and intervention studies. Journal of Children's Services, 3, 4-16.

Cummings, E. and Davies, P. (1994) Children and marital conflict: The impact of family dispute and resolution. New York: Guilford Press

Cummings, E. and Davies, P. (2002) Effects of marital conflict on children: Recent advances and emerging themes in process-oriented research. Journal of Child Psychology and Psychiatry, 43, 1, 31-63.

Davies, K. (2015) Social Work with Troubled Families: A Critical Introduction. London. Jessica Kingsley.

Department for Communities and Local Government and HM Treasury (2013) Massive expansion of Troubled Families programme announced, 24 June 2013 https://www.gov.uk/government/news/massive-expansion-of-troubled-familiesprogramme-announced

Department for Work and Pensions (2014) The Family Test: Guidance for Government Departments.

Department for Work and Pensions (2015a) Government to strengthen child poverty measure. Available at: https://www.gov.uk/government/news/government-tostrengthen-child-poverty-measure

Department for Work and Pensions (2015b) New relationship support offered to expectant parents. Available at: https://www.gov.uk/government/news/newrelationship-support-offered-to-expectant-parents

Duncan Smith, I. (2015) HC Deb, 25 June 2015, c1046. Available from: https://www.theyworkforyou.com/debates/?id=2015-06-25a.1046.0 [Accessed: 04/11/2016]

Family and Childcare Trust, Relate, and Relationships Foundation (2016) Implementing the Family Test: A review of progress one year on.

Farmer, E. and Moyers, S. (2008) Kinship Care: Fostering Effective Family and Friends Placements. London: Jessica Kingsley.

Gabb, J., Klett-Davies, M., Fink, J. and Thomae, M. (2013) Enduring Love: Couple relationships in the $21^{\text {st }}$ century. Interim report. Open University.

Gerard, J., Krishnakumar, A. and Buehler, C. (2006) A prime time for marital/relational intervention: A review of the transition to parenthood literature with treatment recommendations. Journal of Family Issues, 27, 951-975.

Glenn, F. (2007) Growing together drifting apart? Children with disabilities and their parents' relationships. London: OnePlusOne.

Harold, G., Acquah, D., Sellers, R. and Chowdry, H. (2016) What works to enhance inter-parental relationships and improve outcomes for children. DWP ad hoc research report no. 32. London: DWP.

Harold, G.T. and Leve, L.D. (2012) Parents and Partners: How the Parental Relationship affects Children's Psychological Development. In: Balfour, A., Morgan, M., \& Vincent, C. (Eds.) How Couple Relationships Shape Our World: Clinical Practice, Research and Policy Perspectives. London: Karnac.

HM Government (1998) Supporting Families: A consultation document.

HM Government (2011) Announcement: Tackling Troubled Families. Available at: https://www.gov.uk/government/news/tackling-troubled-families

HM Government (2012) Social Justice: transforming lives. London: DWP

HM Government (2014) First ever 'families test' for government. Available at: https://www.gov.uk/government/news/first-ever-families-test-for-governmentpublished

Home Office (1999) Supporting Families: Summary of Responses to the Consultation Document. London: Home Office.

IPPR (2013) Who's Breadwinning? Working mothers and the new face of family support. 
IPPR (2014) The Condition of Britain: Strategies for Social Renewal. London: IPPR.

Klann, N., Hahlweg, K., Baucom, D. and Kroeger, C. (2011) The effectiveness of couple therapy in Germany: a replication study. Journal of marital and family therapy, 37, 2, 200-208.

Lebow, J., Chambers, A., Christensen, A. and Johnson, S. (2012) Research on the treatment of couple distress. Journal of Marital and Family therapy, 38, 1, 145168.

Lindsay, G., Strand, S., Cullen, M., Band, S., Davis, H., Conlon, G., Barlow, J. and Evans, A. (2011) Parenting Early Intervention Programme Evaluation. London: Department for Education.

Mansfield, P. and Collard, J. (1988) The Beginning of the Rest of Your Life: A portrait of newly-wed marriage. London: Macmillan.

Marjoribanks, D. (2016) All Together Now: Stronger relationships for a stronger society. London: Relate.

May, T. (2016) Statement from the new Prime Minister Theresa May. Available at: https://www.gov.uk/government/speeches/statement-from-the-new-primeminister-theresa-may [Accessed: 04/11/16]

Millar, J. (2001) Establishing Family Policy in Britain? Family Matters, 58, 28-33.

Mitnick, D., Heyman, R. and Smith Slep, A. (2009) Changes in relationship satisfaction across the transition to parenthood: A meta-analysis. Journal of Family Psychology, 23, 6, 848-852.

Morris, K., Hughes, N., Clarke, H., Tew, J., Mason, P., Galvani, S., Lewis, A. and Loveless, L. (2008) Think Family: A literature Review of Whole Family Approaches. London. London: Cabinet Office, Social Exclusion Task Force.

Morris, K. (2013) Troubled Families: vulnerable families' experiences of multiple service use. Child and Family Social Work, 18, 198-206.

Office for National Statistics (2015) Statistical Bulletin: Families and Households, 2015.

OnePlusOne (2006) The Edith Dominian Memorial Lecture Proceedings: Fragile Families and Child Wellbeing. London: OnePlusOne.

Page, J., Whitting, G. and McLean, C. (2008) A Review of How Fathers Can be Better Recognised and Supported Through DCSF Policy. London: DCSF.

Pryor, J. and Rodgers, B. (2001) Children in Changing Families: Life after Parental Separation. Oxford: Blackwell

Relationships Foundation (2016) Counting the cost of family failure: 2016 update. Cambridge: Relationships Foundation

Roberts, Y., Brophy, M. and Bacon, N. (2009) Parenting and wellbeing: Knitting families together. London: The Young Foundation.

Shadish, W. and Baldwin, S. (2005) Effects of Behavioral Marital Therapy: A MetaAnalysis of Randomized Controlled Trials. Journal of Consulting and Clinical Psychology, 73, 1, 6-14.

Shadish, W.R. and Baldwin, S.A. (2003) Meta-analysis of MFT interventions. Journal of Marital and Family Therapy, 29, 547-570.

Shapiro, A. and Gottman, J. (2005) Effects on Marriage of a Psycho-CommunicativeEducational Intervention With Couples Undergoing the Transition to Parenthood, Evaluation at 1-Year Post Intervention. Journal of Family Communication, 5, 1-24.

Shonkoff, J.P. and Fisher, P.A. (2013) Rethinking evidence-based practice and twogeneration programs to create the future of early childhood policy. Developmental Psychopathology. 25, 4 (Pt. 2), 1635-53.

Smith, L. and Trinder, L. (2012) Mind the gap: parent education programmes and the family justice system. Child and Family Law Quarterly, 24, 4, 428-451.

Social Exclusion Task Force (2007) Reaching Out: Think Family. London: Cabinet Office. 
Spielhofer, T., Corlyon, J., Durbin, B., Smith, M., Stock, L. and Gieve, M. (2014) Relationship Support Interventions Evaluation. London: Department for Education.

Twenge, J., Campbell, W. and Foster, C. (2003) Parenthood and marital satisfaction: A meta-analytic review. Journal of Marriage and the Family, 65, 3, 574-583.

Walker, J., Barrett, H., Wilson, G. and Chang, Y-S. (2010) Relationships Matter: Understanding the Needs of Adults (Particularly Parents) Regarding Relationship Support. London: Department for Children, Schools and Families

Wastell, D. and White, S. (2012) Blinded by neuroscience: social policy, the family and the infant brain. Families, Relationships and Societies, 1, 3, 397-414(18). 